\title{
The effects of chronic treatment with amitriptyline and diazepam on electrodermal activity in neurotic outpatients
}

\author{
C. D. FRITH, MARILYN STEVENS, EVE C. JOHNSTONE, and D. G. C. OWENS \\ MRC Clinical Research Centre, Harrow, Middlesex, England
}

\begin{abstract}
Electrodermal activity (EDA) was investigated in 162 neurotic outpatients who were randomly assigned to 4 weeks of treatment with various combinations of placebo, amitryptiline, and diazepam. During the measurement of EDA, all patients heard a series of tones. Ninety-one patients experienced this habituation series with no accompanying task (Condition 1), and 71 performed a simple forewarned reaction time task to which the tones were irrelevant (Condition 2). Amitriptyline produced a consistent reduction in skin conductance level and in response magnitudes in both conditions. Diazepam produced a marked reduction in responding in Condition 1, but in Condition 2 responses to the tones were reduced by the attention-engaging reaction time task, and diazepam did not produce a further reduction. Subjects treated with diazepam were more likely to press the RT button erroneously in response to the tones. These subjects had the lowest levels of skin conductance activity. On the other hand, the subjects who made such errors although not treated with diazepam had the highest levels of skin conductance activity. This interaction between the effects of diazepam and task performance in Condition 2 suggests that diazepam affects EDA at a relatively central level, since its effects interact with the attentional demands of the situation.
\end{abstract}

Anxiety states and neurotic depression are the commonest of neurotic illnesses and are usually treated with benzodiazepines and/or tricyclic antidepressants. However, the effects of these drugs on psychological functions remain little understood. At one level, these illnesses have clear associations with extreme arousal states. That is, anxious patients are characterized by overarousal and depressed patients are characterized by underarousal. Electodermal responses and, in particular, the habituation of the electrodermal response have frequently been used as indices of arousal. On this basis, it would seem useful to examine the effects of the two types of drugs on electrodermal responding. A number of studies, most notably those by Lader and Wing (1964), have shown that anxious patients are characterized by high skin conductance activity and a slow rate of habituation. These authors also showed that amylobarbitone and chlordiazepoxide both reduced skin conductance activity and increased the rate of habituation. The evidence on depressed patients is less clear, but two studies have found that skin conductance level and responsivity is abnormally reduced in

The authors are very grateful to the patients for their cooperation with this study. They also wish to thank T. J. Crow for his encouragement and advice in the design and conduct of the study. They are grateful to him and to J. F. Macmillan, I. N. Ferrier, M. Harris, A. Daniels, D. Leigh, and J. S. Price for their help in referring cases. This study was conducted under the auspices of the Ethical Committee of Northwick Park Hospital and was carried out according to its rules. The authors' mailing address is: CRC Psychiatry, Watford Road, Harron HAl 3UJ, U.K. patients with more severe depression (Lader \& Wing, 1969; Noble \& Lader, 1971).

On the basis of this evidence, we would expect anxiolytics such as the benzodiazepines to reduce skin conductance activity and speed up the habituation process. Farharmoud, Harrison, Pare, Turner, and Wynn (1979) found that $2 \mathrm{mg}$ of lorezepam lowered skin conductance levels and decreased the number of spontaneous fluctuations. Itil, Schneider, and Fredrickson (1981) found that $10 \mathrm{mg}$ diazepam produced a marked reduction in skin conductance level. Antidepressant drugs, on the other hand, should increase responsivity and slow down habituation. However, most antidepressant drugs, particularly the tricyclics, such as amitriptyline, have anticholinergic effects. Given the cholinergic innervation of sweat glands this should lead to a reduction of electrodermal activity by these drugs (e.g., Patterson \& Venables (1981) found that scopolamine significantly reduced skin conductance responsivity). However, this effect need have nothing to do with changes in arousal and might only reflect peripheral actions of the drug.

Although anxiety and depression may at one level be associated with changes in arousal, abnormal levels of arousal are not a sufficient characterization of these states. Extreme levels of arousal are not necessarily unpleasant and can be beneficial in appropriate circumstances. At another level there must also be cognitive changes associated with the symptoms of anxiety and depression. The investigation of habituation is of particular relevance to this aspect of neurotic illness, since this process has 
a large cognitive component, as well as an arousal component (Sokolov, 1963): habituation presupposes that a mental representation of the stimulus has been created. In the first condition investigated in this study, subjects heard a simple habituation series with a "novel" tone embedded towards the end. While there is a strong cognitive component in both the habituation to the standard tones and in the response to the novel tone, the precise degree of cognitive involvement is not clear, since some subjects may, contrary to instructions, actively attend to the tones.

Therefore, in the second condition examined in this study, the attention of subjects was manipulated more directly by asking them to perform a simple reaction time task during the habituation series. The effect of the taskirrelevant tones on the performance of this task gave a simple indication of the degree to which subjects were distracted by the irrelevant tones.

An interaction between the effects of a drug and the degree of attention to the irrelevant tones would strongly imply an effect of the drug on attention and information processing. It should be possible to observe such interactions in Condition 2 and also in a comparison of Condition 1 and Condition 2. For example, Frith and Allen (1983) found that habituation was speeded up by a secondary task (as in Condition 2), presumably because attention was directed away from the tones. The ability to ignore irrelevant stimuli and concentrate attention on the task in hand might well be impaired in states of anxiety, and it is therefore plausible that an anxiolytic drug, such as diazepam, could reinstate this ability.

The therapeutic effects of the treatments used in this study have already been reported (Johnstone, Owens, Frith, McPherson, Dowie, Riley, and Gold, 1980). All patients showed a marked recovery from their symptoms of anxiety and depression, and there was little evidence that the two active drugs were any more effective than placebo. We have already reported on relationships between clinical ratings and EDA (Johnstone, Bourne, Crow, Frith, Gamble, Lofthouse, Owen, Owens, Robinson, \& Stevens, 1981), but have not given a detailed account of the effects of the drugs on EDA. Investigation of electrodermal activity can provide additional independent evidence as to whether either of the drugs had produced changes in arousal and/or cognition.

Finally, if it can be shown that these two drugs have marked effects on electrodermal activity, this would have to be taken into account when interpreting data from patients such as schizophrenics. These patients often receive treatment with benzodiazepines and anticholinergics in addition to neuroleptic drugs.

\section{METHOD}

\section{Subjects}

This study concerns 240 nonpsychotic outpatients, between the ages of 18 and 65 , who were not dependent on drugs or alcohol. These patients had been selected on the basis of a score of at least 2 on observed depression, observed anxiety, or both, on the Standardised Psychiatric
Interview devised by Goldberg, Cooper, Eastwood, Kedward, and Shepherd (1970). The neurotic/endogenous rating devised by Carney, Roth, and Garside (1965) was also applied, and those within the endogenous range were not selected. Patients who, within the past 6 months, had had tricyclics or benzodiazepines for at least 1 week in dosages equivalent to those used in this study were not selected.

Participation involved five consecutive weekly attendances at a special clinic devoted to this purpose and a 4-week course of tablets. Electrodermal activity was assessed on the first attendance (pretreatment) and the fourth attendance (after 3 weeks of treatment).

The patients were allocated randomly to one of four treatment groups. Each patient was given two sets of tablets: placebo amitriptyline and placebo diazepam, placebo amitriptyline and diazepam, amitriptyline and placebo diazepam, amitriptyline and diazepam. The dosage of amitriptyline was $25 \mathrm{mg}$ BD and $50 \mathrm{mg}$ nocte for the $1 \mathrm{st}$ week and $25 \mathrm{mg}$ TD and $75 \mathrm{mg}$ nocte for the following 3 weeks. That of diazepam was $5 \mathrm{mg} \mathrm{BD}$ and nocte for the 1st week and $5 \mathrm{mg}$ TID and nocte for the following 3 weeks.

Neither the patients nor the people assessing them knew what treatment they were receiving.

\section{Electrodermal Activity}

Skin conductance was measured directly using the method of Lykken and Venables (1971) and a Devices DC amplifier and chart recorder. Silver-silver chloride disk electrodes were attached to the second phalanges of the first and second fingers of the left hand; the fingers were first masked with adhesive rings exposing $1 \mathrm{~cm}^{2}$ of skin, and electrodes were filled with KY lubricating jelly. Skin conductance and event markers were recorded on tape and subsequently analyzed on a PDP-11 computer, using the ELSA software package. A 12.8-sec segment (64 samples) of skin conductance was analyzed for each stimulus beginning $1.6 \mathrm{sec}$ (8 samples) before the onset of the stimulus. Skin conductance within this segment was sampled every $200 \mathrm{msec}$, and each sample was the average of five 40 -msec subsamples. The range and base level values for each segment were supplied so that skin conductance could be converted to real units (micromhos) for subsequent response marking. An automatic procedure for detecting responses was applied, based on that described by Martin, Levy, and Slubicka (1975). This procedure identifies response onsets on the basis of a specified rate of increase of skin conductance. An onset was deemed to have occurred if the rate of increase of skin conductance exceeded $0.0125 \mathrm{Mmhos} / \mathrm{sec}$ for at least $800 \mathrm{msec}$. A new onset could not occur until the rate of increase had fallen below $0.01 \mathrm{Mmhos} / \mathrm{sec}$. Before identifying the responses, the data had been smoothed twice, using triangular weights. A fluctuation was considered to be linked to a stimulus, and therefore to be a response, if its onset occurred between 1 and $4 \mathrm{sec}$ after the onset of the tone. All other fluctuations were labeled spontaneous fluctuations. The distributions of base level skin conductance and response amplitudes were positively skewed, and therefore a logarithmic transformation was applied to these measures prior to analysis of variance. A subject was considered to have habituated to a particular series of stimuli if he failed to give a response to two successive stimuli.

\section{Experimental Conditions}

Two experimental conditions were investigated in this study. The first applied to the first half of the sequence of patients entering the trial, and the second applied to the remaining patients.

Condition 1. The subject sat comfortably in an armchair wearing headphones. After a short pause, he or she heard 17 tones of $85 \mathrm{~dB}$ and $1000 \mathrm{~Hz}$. The tones lasted for $1 \mathrm{sec}$ each, and there was a variable interval of between 15 and $25 \mathrm{sec}$ between tones. Between the 14th and 15 th tone, there was an additional $100-\mathrm{dB}$ tone at $2000 \mathrm{~Hz}$. The subjects were warned in advance that one of the tones would be rather loud. The subjects were told that they did not have to respond to the tones in any way. Rather, they should ignore the tones and try to relax. Records from 91 patients were available for this condition. There were 30 men and 61 women aged between 18 and 57 years. There were no differences in age or sex ratio between the four treatment groups.

Condition 2. The subject sat in an armchair and wore headphones. He or she faced a small VDU controlled by a PDP-11 computer and 
held a pushbutton in his or her right hand. After a short pause, the word READY appeared on the screen and stayed there for $9 \mathrm{sec}$. On the 10th second, the word PRESS appeared and the subject had to press the button held in his or her right hand as quickly as possible. There were 21 such trials, separated by a random interval of between 15 and $30 \mathrm{sec}$. From trial 6 onwards, an $85-\mathrm{dB}$ tone of $1000 \mathrm{~Hz}$ was presented in conjunction with each trial. For half the 16 trials, this tone occurred at random between the 2 nd and 8 th second after the READY signal, that is, while the subject was engaged in the forewarned reaction time task. For the other half of the trials, the tone occurred at random between the 2nd and 8th second after the PRESS signal, that is, when the subject was not engaged in his or her task. The two types of tone trial (tone inside task, tone outside task) occurred in pairs, with the order within each pair being determined at random. The subject was told that the tones were irrelevant to the task and should be ignored. Records from 71 patients were available for this condition. There were 20 men and 51 women aged between 20 and 57 years. There were no differences in age or sex ratio between the four treatment conditions.

\section{RESULTS}

The effects of the various treatment regimes on symptoms have been reported already (Johnstone et al., 1980). Given the very small differential effects of treatments on symptoms, it is very unlikely that differences in the effects of the drugs on electrodermal activity are a secondary consequence of differences in symptomatology. Although patients had all been tested both before treatment began and after 3 weeks of treatment, we shall report the results from only the final test here. This permits a statistically more tractable between-subject design and also ensures that differences between subjects are relatively small, since at this time their symptoms were largely remitted.

\section{Condition 1}

Table 1 shows the main effects of treatment on some quantitative skin conductance measures. There were a number of significant effects of diazepam. In the patients so treated, initial base level was lower $[F(1,87)=7.40$, $\mathrm{p}<.01$ ] and mean response magnitude to the 14 habituation trials (excluding nonresponders) was smaller $[F(1,63)$ $=7.56, \mathrm{p}<.01 \mathrm{~J}$. There was no effect of treatment on the amplitude of spontaneous fluctuations. The magnitude of the response to the novel tone was significantly smaller in the patients receiving amitriptyline $[\mathrm{F}(1,63)=4.04$, $P<.05]$, but was not affected by diazepam. There was no effect of treatment on the magnitude of responses to the three tones following the novel stimulus.

Table 2 shows some qualitative effects of treatment in Condition 1. There was a significant effect of diazepam on the distribution of nonhabituators and nonresponders (chi-square test and Pages test for trends, $z=3.57$, $\mathrm{p}<.001$ ), such that this treatment increased the proportion of nonresponders and decreased the proportion of nonhabituators. Diazepam also significantly reduced the number of spontaneous fluctuations $(\mathrm{z}=2.15, \mathrm{p}<.05)$.

Table 1

Effects of Treatment on Quantitative Aspects of EDA: Condition 1

\begin{tabular}{|c|c|c|c|c|c|c|}
\hline & \multicolumn{3}{|c|}{ Diazepam } & \multicolumn{3}{|c|}{ Amitriptylin } \\
\hline & Off(43) & On(48) & Sig. & Off(47) & On(44) & Sig. \\
\hline \multicolumn{7}{|c|}{ Base Level ( $\mu$ mhos) } \\
\hline $\ln (\mathrm{BL})$ & $\begin{array}{c}2.47 \\
0.90 \pm .18\end{array}$ & $\begin{array}{c}1.48 \\
0.39 \pm .19\end{array}$ & $<.01$ & $\begin{array}{c}2.14 \\
0.76 \pm .18\end{array}$ & $\begin{array}{c}1.71 \\
0.54 \pm .26\end{array}$ & n.s. \\
\hline \multicolumn{7}{|c|}{ Response Magnitude ( $\mu$ mhos) } \\
\hline $\ln (R * 100+1)$ & $\begin{array}{c}.080 \\
2.19 \pm .30\end{array}$ & $\begin{array}{c}.035 \\
1.50 \pm .27\end{array}$ & $<.01$ & $\begin{array}{c}.062 \\
1.98 \pm .26\end{array}$ & $\begin{array}{c}.045 \\
1.71 \pm .32\end{array}$ & n.s. \\
\hline \multicolumn{7}{|c|}{ Spontaneous Fluctuation Amplitude ( $\mu$ mhos) } \\
\hline $\ln (A * 100+1)$ & $\begin{array}{c}.058 \\
1.92 \pm .13\end{array}$ & $\begin{array}{c}.067 \\
2.04 \pm .16\end{array}$ & n.s. & $\begin{array}{c}.071 \\
1.95 \pm .13\end{array}$ & $\begin{array}{c}.065 \\
2.01 \pm .20\end{array}$ & n.s. \\
\hline \multicolumn{7}{|c|}{ Response Magnitude (Novel Tone) ( $\mu$ mhos) } \\
\hline $\ln (R * 100+1)$ & $\begin{array}{c}.163 \\
2.85 \pm .37 \\
\end{array}$ & $\begin{array}{c}.071 \\
2.09 \pm .38 \\
\end{array}$ & n.s. & $\begin{array}{c}.179 \\
2.94 \pm .34 \\
\end{array}$ & $\begin{array}{c}.064 \\
2.00 \pm .40\end{array}$ & $<.05$ \\
\hline
\end{tabular}

Table 2

Effects of Treatment on Qualitative Aspects of EDA: Condition 1

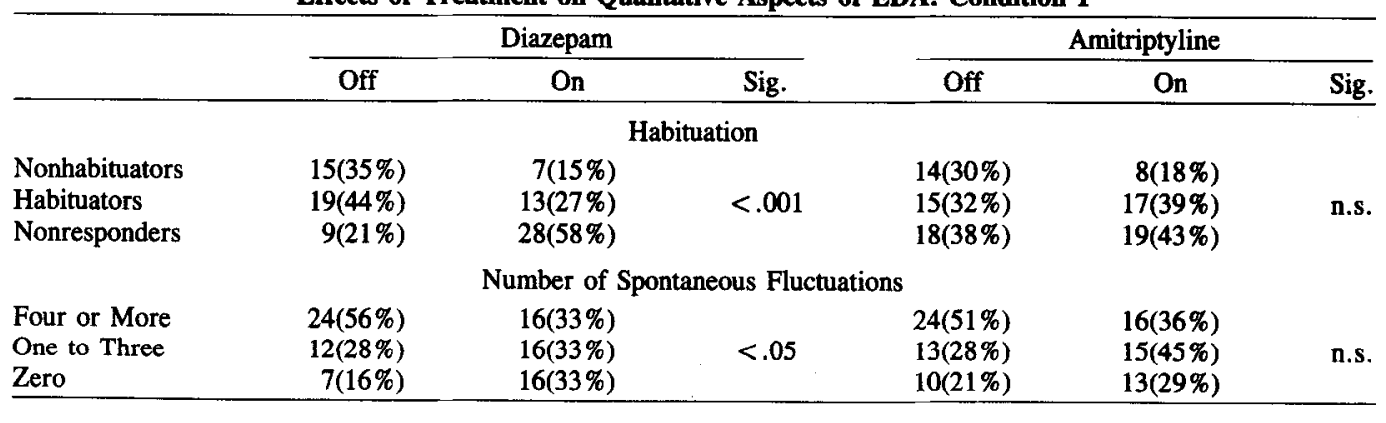


Table 3

Effects of Treatment on Quantitative Aspects of EDA: Condition 2

\begin{tabular}{|c|c|c|c|c|c|c|}
\hline & \multicolumn{3}{|c|}{ Diazepam } & \multicolumn{3}{|c|}{ Amitriptyline } \\
\hline & Off(33) & On(38) & Sig. & Off(35) & On(36) & Sig. \\
\hline \multicolumn{7}{|c|}{ Errors: Number of Subjects } \\
\hline & $8(24 \%)$ & $19(50 \%)$ & $<.05$ & $13(37 \%)$ & $14(39 \%)$ & n.s. \\
\hline \multicolumn{7}{|c|}{ Base Level ( $\mu$ mhos) } \\
\hline $\ln (\mathrm{BL})$ & $\begin{array}{c}2.36 \\
0.86 \pm .23\end{array}$ & $\begin{array}{c}1.57 \\
0.45 \pm .23\end{array}$ & n.s. & $\begin{array}{c}2.27 \\
0.82 \pm .23\end{array}$ & $\begin{array}{c}1.64 \\
0.49 \pm .24\end{array}$ & n.s. \\
\hline \multicolumn{7}{|c|}{ Response Magnitude, Warning ( $\mu$ mhos) } \\
\hline $\ln (R * 100+1)$ & $\begin{array}{c}.018 \\
1.02 \pm .26\end{array}$ & $\begin{array}{c}.019 \\
1.08 \pm .28\end{array}$ & n.s. & $\begin{array}{c}.024 \\
1.24 \pm .27\end{array}$ & $\begin{array}{c}.014 \\
0.86 \pm .27\end{array}$ & n.s. \\
\hline \multicolumn{7}{|c|}{ Response Magnitude, Imperative Signal ( $\mu$ mhos) } \\
\hline $\ln (\mathrm{R} * 100+1)$ & $\begin{array}{c}.028 \\
1.34 \pm .40\end{array}$ & $\begin{array}{c}.032 \\
1.43 \pm .30\end{array}$ & n.s. & $\begin{array}{c}.046 \\
1.73 \pm .41\end{array}$ & $\begin{array}{c}.018 \\
1.04 \pm .28\end{array}$ & $<.05$ \\
\hline \multicolumn{7}{|c|}{ Response Magnitude, Irrelevant Tones ( $\mu$ mhos) } \\
\hline $\ln (\mathbf{R} * 100+1)$ & $\begin{array}{c}.069 \\
2.07 \pm .25\end{array}$ & $\begin{array}{c}.048 \\
1.76 \pm .32\end{array}$ & n.s. & $\begin{array}{c}.086 \\
2.26 \pm .29\end{array}$ & $\begin{array}{c}.038 \\
1.57 \pm .25\end{array}$ & $<.02$ \\
\hline \multicolumn{7}{|c|}{ Spontaneous Fluctuation Amplitude ( $\mu$ mhos) } \\
\hline $\ln (A * 100+1)$ & $\begin{array}{c}.050 \\
1.79 \pm .17\end{array}$ & $\begin{array}{c}.067 \\
2.04 \pm .21 \\
\end{array}$ & n.s. & $\begin{array}{c}.063 \\
1.99 \pm .17\end{array}$ & $\begin{array}{c}.053 \\
1.84 \pm .20\end{array}$ & n.s. \\
\hline
\end{tabular}

\section{Condition 2}

In contrast to Condition 1, we have for Condition 2 a crude measure of the extent to which subjects successfully carried out the instructions given by the experimenter. Although no subject failed to press the button in response to the stimulus PRESS, a number erroneously pressed the button on the first occasion that the tone occurred between the READY and the PRESS signals. This was in spite of the fact that all subjects had already performed the same task 4 weeks earlier. These errors were significantly more likely to occur in subjects treated with diazepam $(\mathrm{z}=2.21$, $\mathrm{p}<.05$; see Table 3). In analyzing the effects of treatment on skin conductance variables, it was clearly important to take into account this aspect of the subjects' behavior. The treatment groups were therefore subdivided on the basis of whether or not they made errors before applying analysis of variance. Table 3 shows the main effects of treatment on some quantitative skin conductance measures in Condition 2. Amitriptyline elicited no effect on base level or response magnitude to the warning signals (READY), but it significantly reduced response magnitudes to the imperative signals (PRESS) $[\mathrm{F}(1,44)=$ $5.06, \mathrm{p}<.05]$ and the tones $[\mathrm{F}(1,44)=5.71, \mathrm{p}<.02]$. There were no significant main effects of diazepam on the skin conductance variables, but there were a number of significant interactions between diazepam and task performance, which are shown in Table 5. There were significant interactions between diazepam and task performance for base level $[F(1,44)=4.07, p<.05]$, response magnitudes to warning signals $[\mathrm{F}(1,44)=4.73$, $p<.05]$, imperative signals $[F(1,44)=4.76, p<.05]$, and tones $[\mathrm{F}(1,44)=6.51, \mathrm{p}<.01]$.

There were no effects of treatment on the form of the habituation curves to the various stimuli or on the amplitude of spontaneous fluctuations.
There were no effects of treatment on habituation status for any of the three types of stimuli.

\section{Comparison of Conditions 1 and 2}

It is striking that diazepam had a large effect on responsivity in Condition 1 (fewer trials to habituation, fewer spontaneous fluctuations, etc.), but not in Condition 2 .

Table 4

Effects of Diazepam on Quantitative Aspects of EDA: Condition 2, Interactions with Task Performance

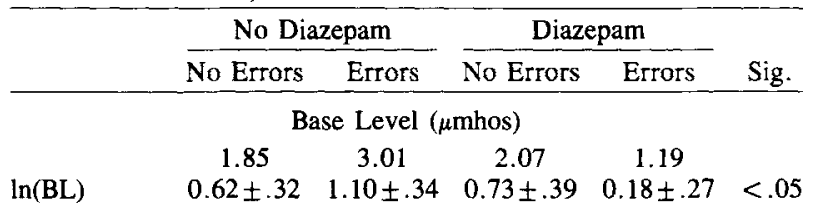

Response Magnitude, Warning Signals ( $\mu$ mhos)

$$
\begin{array}{llll}
.014 & .022 & .034 & .009
\end{array}
$$

$\ln (\mathrm{R} * 100+1) \quad .88 \pm .33 \quad 1.16 \pm .46 \quad 1.49 \pm .43 \quad 0.67 \pm .36<.05$

Response Magnitude, Imperative Signals ( $\mu$ mhos)

$$
\begin{array}{llll}
.024 & .033 & .063 & .014
\end{array}
$$

$\ln \left(R^{*} 100+1\right) \quad .23 \pm .35 \quad 1.45 \pm .92 \quad 1.99 \pm .52 \quad 0.88 \pm .32<.05$

Response Magnitude, Irrelevant Tones ( $\mu$ mhos)

$$
\begin{array}{llll}
.042 & .111 & .070 & .032
\end{array}
$$

$\begin{array}{lllll}\ln (\mathrm{R} * 100+1) & .64 \pm .29 & 2.49 \pm .47 & 2.08 \pm .51 & 1.44 \pm .40<.01\end{array}$

\section{Table 5}

Effects of Diazepam on Habituation to Tones: Condition 1 vs. Condition 2

\begin{tabular}{lrrrrrr}
\hline & \multicolumn{2}{c}{ No Diazepam } & & \multicolumn{2}{c}{ Diazepam } & \\
\cline { 2 - 3 } \cline { 5 - 6 } & \multicolumn{1}{c}{$\mathrm{C} 1$} & \multicolumn{1}{c}{$\mathrm{C} 2$} & & $\mathrm{C} 1$ & $\mathrm{C} 2$ & Sig. \\
\hline Nonhabituators & $15(35 \%)$ & $3(9 \%)$ & & $7(15 \%)$ & $5(13 \%)$ & \\
Habituators & $19(44 \%)$ & $20(61 \%)$ & & $13(27 \%)$ & $17(45 \%)$ & $<.05$ \\
Nonresponders & $9(21 \%)$ & $10(30 \%)$ & $28(58 \%)$ & $16(42 \%)$ & \\
\hline
\end{tabular}


This difference between conditions was assessed formally by comparing the habituation status of the subjects across the four treatments and the two conditions. There was a significant interaction between diazepam and condition $(\mathrm{z}=2.48, \mathrm{p}<.025)$. As can be seen in Table 5, this was due a difference between conditions for the subjects who received no diazepam. In this treatment category, there was a much higher proportion of nonhabituators in Condition 1.

\section{DISCUSSION}

It is clear from these results that small doses of diazepam and amitriptyline administered chronically have marked effects on skin conductance responsivity. However, the effects of the two drugs were distinctively different.

\section{Effects of Amitriptyline}

Amitriptyline consistently reduced responsivity in terms of base level, number of responses, and response amplitude. However, this effect was small. Only one of these measures was significantly reduced in Condition 1, whereas the majority of these effects were significant in Condition 2. This difference between conditions was not due, however, to a different effect of the drug, but to a reduction of within-group variability in Condition 2 . This was achieved by grouping subjects in this condition on the basis of task performance. Such grouping was not possible in Condition 1. Since these effects of amitriptyline do not interact with task performance or with the information processing requirements of the conditions, they presumably occur at a relatively late or peripheral stage in the control of sweat gland activity. Thus, the effects of amitriptyline on skin conductance probably reflect its anticholinergic properties and have little to do with its antidepressant effects.

\section{Effects of Diazepam}

Although diazepam also reduced responsivity, it did it in an entirely different way from amitriptyline. There were strong interactions between diazepam effects and both the nature of the condition and task performance. Thus, in general, diazepam reduced responsivity in Condition 1 and not in Condition 2. This is a consequence of the additional task in Condition 2. In Condition 1, diazepam reduced responses to the irrelevant tones. In Condition 2 , responses to the irrelevant tones were reduced by the necessity of attending to the buttonpressing task (Frith \& Allen, 1983) and diazepam did not have any additional effect. This interaction with the information processing requirements of the task suggests that diazepam affects sweat gland activity at a relatively early or central stage. Furthermore, the ability of diazepam to reduce responses to irrelevant tones when no other distractions are available could obviously relate to its anxiolytic properties. The interaction of diazepam with task performance in Condition 2 is also consistent with this interpretation. Two main processes are required to carry out the very simple but- tonpressing task in Condition 2. First, all stimuli must be processed in order to identify the imperative signal, and second, the button must be pressed. Insufficient processing could result in the button's being pressed to irrelevant stimuli. However, these errors could also occur because of an extreme readiness to press the button. This first mēchanism for errors might be associated with too low a level of arousal/activation; the second mechanism might be associated with levels of arousal/activation that were above optimum. Diazepam increased the number of buttonpressing errors overall, presumably by lowering arousal below optimum and reducing the amount of attention paid to the stimuli. This interpretation is supported by the observation that the subjects who made errors under diazepam were less responsive in terms of skin conductance than those who did not make errors under diazepam. On the other hand, those few subjects who made mistakes although not receiving diazepam showed the opposite pattern. They were the most responsive in terms of skin conductance, suggesting that they made mistakes because they were overaroused and had an excessive readiness to press the button. This result suggests that diazepam would help highly aroused people by reducing the probability that they would respond to inappropriate stimuli. However, diazepam will impair the performance of those already at an optimum level of activation for a particular task.

\section{Implications for the Use of the Skin Conductance Response as an Index of Psychopathy}

Skin conductance is widely used as an index of attention and arousal in the study of psychopathology, particularly that associated with schizophrenia. Our results suggest that such studies must be treated with caution if the patients were receiving either anticholinergics or benzodiazepines. This will frequently be the case with schizophrenic patients. The majority of patients treated with neuroleptics will also receive anticholinergics to combat motor side effects. In addition, schizophrenic patients will frequently be receiving benzodiazepam hypnotics (e.g., nitrazepam), and, on occasion, drugs such as diazepam will also be used as an aid in their management. These treatments will almost certainly affect the pattern of skin conductance activity shown by these patients.

\section{REFERENCES}

Carney, M. W. P., Roth, M., Garside, R. F. (1965). The diagnosis of depression syndromes and the prediction of ECT response. British Journal of Psychiatry, 111, 659-674.

Farhoumoud, N., Harrison, J., Pare, C. M. B., Turner, P., \& WyNN, S. (1979). The effects of high dose oxprenolol on stressinduced physical and psychophysiological variables. Psychopharmacology, 64, 365-368.

Frith, C. D., ALLEN, H. A. (1983). The skin conductance orienting response as a index of attention. Biological Psychology, 17, 27-39. GoldberG, D. P., Cooper, E., Eastwood, N. R., Kedward, H. B., \& SHEPHERD, M. (1970). A standardised psychiatric interview for use in community surveys. British Journal of Preventive and Social Medicine, 24, 18-23.

ItiL, T. M., SChneider, S. J., \& Fredrickson, J. W. (1981). The 
replicability of the psychophysiological effects of diazepam. Biological Psychiatry, 16, 65-70.

Johnstone, E. C., Bourne, R. C., Crow, T. J., Frith, C. D., GamBle, S., Lofthouse, R., OWen, F., OWens, D. G. C., Robinson, J., \& STEVENS, M. (1981). The relationships between clinical response, psychophysiological variables and plasma levels of amitriptyline and diazepam in neurotic outpatients. Psychopharmacology, 72, 233-240. Johnstone, E.C., Owens, D. G. C., Frith, C.D., McPherson, K., Dowie, C., Riley, G., \& Gold, A. (1980). Neurotic illness and its response to anxiolytic and antidepressant treatment. Psychological Medicine, 10, 321-328.

LADER, M. H., \& WING, L. (1964). Habituation of the psycho-galvanic reflex in patients with anxiety states and in normal subjects. Journal of Neurology, Neurosurgery and Psychiatry, 27, 210-218.

LADER, M. H., \& WING, L. (1969). Physiological measures in agitated and retarded depressed patients. Journal of Psychiatry Research, 7, 89-100.
LykKen, D. T., \& Venables, P. H. (1971). Direct measurement of skin conductance: A proposal for standardization. Psychophysiology, 8, 656-672.

MARTIN, I., LeVy, A.B., \& SlubickA, B. (1975). Response relationships in SRR conditioning. Psychophysiology, 12, 83-89.

NoBle, P. J., \& LADER, M. H. (1971). The symptomatic correlates of the skin conductance changes in depression. Journal of Psychiatry Research, 9, 61-69.

Patterson, T., \& Venables, P. H. (1981). Bilateral skin conductance and the pupillary light-dark reflex: Manipulation by chlorpromazine, haloperidol, scopolamine and placebo. Psychopharmacology, 73, 63-39.

Sokolov, Y. N. (1963). Perception and the conditioned reflex. Pergamon Press: Oxford.

(Manuscript received February 1, 1984; revision accepted for publication June 20, 1984,) 